\title{
UNA OBRA DESCONOCIDA DEL PINTOR MATÍAS JIMENO: EL RETABLO DE LA ASUNCIÓN EN LA IGLESIA DE SAN GIL ABAD DE VILLANUEVA DE JILOCA (ZARAGOZA)
}

La personalidad artística del pintor Matías Jimeno (Ximeno) presenta un perfil cada vez más definido gracias a las sucesivas aportaciones que, en un goteo espaciado pero continuo, se han venido produciendo en las últimas décadas. Las nuevas informaciones que hoy poseemos han solventado algunas dudas y permiten completar y matizar los trabajos casi simultáneos de Diego Angulo Íñiguez-Alfonso E. Pérez Sánchez ${ }^{1}$ y Rosa López Torrijos ${ }^{2}$, verdaderos hitos en la fortuna historiográfica del artista desde que Antonio Ponz nos proporcionara las primeras noticias ${ }^{3}$, luego completadas - con algunos datos no corroborados y de validez incierta- por Juan A. Ceán ${ }^{4}$ y el conde de la Viñaza 5.

Sin olvidar las contribuciones de la década de 1970, debidas -entre otros- a Diego Angulo, Jesús Urrea, J. Miguel Serrera y José L. Arrese ${ }^{6}$, es preciso actualizar la bibliografía del artista con las publicaciones más recientes, a cargo de Emilia Montaner ${ }^{7}$, José M. Muñoz ${ }^{8}$, Juan A. Marco ${ }^{9}$, Enrique Valdivieso ${ }^{10}$ e Ismael Gutiérrez ${ }^{11}$.

Pese a los avances conseguidos, hasta la fecha no se ha podido documentar el origen del artista y se desconocen también los pormenores de su formación, aunque tradicionalmente se le ha supuesto un aprendizaje en la Corte y se le ha considerado discípulo de Vicente Carducho ${ }^{12}$, si bien Jimeno pudo perfectamente tomar contacto con la pintura del florentino, sin necesidad de un contacto personal, a través de las obras ejecutadas por éste en la década de 1630 para algunas localidades

\footnotetext{
${ }^{1}$ Angulo Íñiguez, Diego y Pérez Sánchez, Alfonso E.: Pintura madrileña del segundo tercio del siglo XVII. Madrid, Instituto Diego Velázquez (CSIC), 1983, pp. 376-387 y láms. 377-399.

${ }^{2}$ López Torrijos, Rosa: La mitología en la pintura española del Siglo de Oro, col. “Arte. Grandes Temas”. Madrid, Cátedra, 1985, passim (y en especial p. 93). La autora se centra en los cuadros (entre ellos varios de tema mitológico) realizados por Jimeno para el palacio del Buen Retiro y que aparecen consignados en los inventarios reales.

3 Ponz Piquer, Antonio: Viaje de España. Madrid, 1972 (1 ${ }^{\text {a }}$ ed. 1772-1794), t. XIII, p. 25.

${ }^{4}$ Ceán Bermúdez, Juan Agustín: Diccionario histórico de los más ilustres profesores de las bellas artes en España. Madrid, reales academias de San Fernando y de la Historia, 1965 (1 $1^{\text {a }}$ ed. 1800), t. VI, p. 14.

5 Viñaza, Cipriano Muñoz y Manzano, conde de la: Adiciones al Diccionario histórico de los más ilustres profesores de las Bellas Artes en España de D. Juan Agustín Ceán Bermúdez. Madrid, Tipografía de los Huérfanos, 1894, t. IV, pp. $62-64$.

6 Angulo Íñiguez, Diego: Pintura del siglo XVII, "Ars Hispaniae. Historia Universal del Arte Hispánico”, vol. XV. Madrid, Plus Ultra, 1971, pp. 225-226. Urrea, Jesús: "Notas para el estudio del arte en León (V). La pintura del siglo XVII en León", Tierras de León. León, 29, 1977, pp. 28 y 33. Serrera, J. Miguel: "Una Riña de pícaros de Matías Jimeno", Archivo Español de Arte. Madrid, t. LII, núms. 205-208, 1979, pp. 79-80. Arrese, José L.: El Arte, la fundación y la medalla de honor. Madrid, Fundación Arrese, 1980, p. 247.

${ }^{7}$ Montaner, Emilia: "Pintores de la escuela madrileña en tierras de Guadalajara", Wad-Al Hayara. Guadalajara, 15, 1988, pp. 388-390. La autora se centra en las pinturas del retablo mayor de la parroquial de Santa María del Rey en Atienza, obras que probablemente proceden de los Jerónimos de Sigüenza.

${ }^{8}$ Muñoz Jiménez, José M.: "La arquitectura del renacimiento en el valle del Henares: relevancia de la villa de Cogolludo", Actas del II Encuentro de Historiadores del Valle del Henares. Guadalajara, 1990, pp. 641 y ss.

${ }^{9}$ Marco Martínez, Juan A.: "El pintor Matías Jimeno. Su etapa en Sigüenza. Los retablos de Pastrana y Arbancón", Anales Seguntinos. Sigüenza, vol. IV, núm. 10, 1994, pp. 9-31.

10 Valdivieso, Enrique: "Un retrato de la madre Ana de San Agustín por Matías Jimeno", Homenaje al profesor Martín González. Valladolid, Universidad, 1995, pp. 569-570.

11 Gutiérrez Pastor, Ismael: "L'expulsió dels mercaders del temple", Llums del Barroc (catálogo de exposición). Gerona, Fundació Caixa de Girona, 2004, pp. 56-57.

12 El profesor Ismael Gutiérrez (Gutiérrez Pastor, Op. Cit.) ha subrayado recientemente esta influencia carduchesca aludiendo a ciertos detalles de los retratos inéditos de fundadores y abades conservados en Santa María de Huerta (Soria).
} 
guadalajareñas. En cualquier caso, su vinculación con la tradición madrileña de las primeras décadas del s. XVII es evidente en sus cuadros, que muestran, junto a ciertos resabios contrarreformistas, una incipiente preocupación naturalista y un conocimiento del tenebrismo de Caravaggio y Ribera.

Jimeno está documentado como vecino de Guadalajara en 1635 y 1636, y en diciembre de este último año aparece citado en un contrato como pintor residente en Pastrana (Guadalajara), aunque ejercía también de dorador y pintor de brocha gorda. Tras los trabajos en esta localidad, que parecen remontarse a 1635, desaparece su rastro hasta 1644, fecha en que reaparece como vecino de Sigüenza (Guadalajara), sin que se conozcan los motivos del traslado. En esta localidad vivió y trabajó hasta su muerte el 10 de agosto de 1657. Su actividad cierta se desarrolla entre 1639, fecha del Crucificado del ático del retablo mayor de la colegiata de Pastrana, y 1656, año en que firma las pinturas del retablo de Arbancón (Guadalajara) ${ }^{13}$.

Si exceptuamos el notable conjunto de cuadros ejecutados para el Buen Retiro -sin datación precisa-, el grueso de su producción se circunscribe casi por entero a la provincia de Guadalajara (y en concreto a los límites del antiguo obispado de Sigüenza), e incluso la presencia de dos lienzos suyos (un San Jerónimo de 1644 y un San Bartolomé de 1651) en la catedral de León pudo deberse a un donativo del obispo Bartolomé Santos de Risoba, que ocupó consecutivamente las sedes leonesa y seguntina ${ }^{14}$. Su supuesto destierro, tradición existente en Arbancón de la que se hizo eco el conde de la Viñaza, carece de constatación documental, y el único argumento que la apoya es que a partir de su establecimiento en Sigüenza parece cesar su producción de mitologías, si bien la temática de sus obras siguió siendo variada, con un marcado interés por el paisaje.

Jimeno pasa por ser un pintor de producción local, prestigiado por su mayor calidad, que no pasa de ser discreta desde una óptica más amplia. Excepcional puede considerarse su costumbre de firmar y fechar las pinturas, casi siempre como "Mathia Ximeno" (también "Jimeno" o "X"), seguido de "faciebat" y del año; en el caso de retablos, sólo firma los lienzos de cierta entidad.

En su producción se aprecian influencias flamencas, sobre todo en los paisajes con escenas mitológicas o bíblicas, y en otras composiciones para las que se lucra igualmente de diseños italianos. También es clara la incidencia de lo veneciano, especialmente en el uso de colores atizianados. Sus figuras, en general, son bastante uniformes en la fisonomía, rígidas en la pose y algo frías en la expresión, lo que produce un efecto general de arcaísmo, algo atenuado cuando el pintor se apoya en invenciones ajenas, lo que origina apreciables desigualdades en su producción y al mismo tiempo impide trazar una evolución clara en su estilo.

Respecto a la utilización de modelos, pueden señalarse como ejemplos una estampa de Francesco Villamena de 1603 -muy copiada posteriormente- que Jimeno reproduce con ligeros cambios en la Riña de pícaros (Mairena del Alcor, Sevilla, colección Bonsor) ${ }^{15}$, pero también composiciones flamencas de fines del s. XVI, como se aprecia en el paisaje de fondo del Crucificado de Pastrana o en la Expulsión de los mercaderes del templo (Madrid, colección particular), donde se sirve de una creación de Hans Vredemans de Vries para la ambientación arquitectónica y de escenas de mercado como las de Joachim Beuckelaert o Peter Aertsen para las figuras ${ }^{16}$.

A la producción documentada hasta ahora incorporamos una nueva obra, conservada en la parroquial de Villanueva de Jiloca (Zaragoza), con la que se amplía el dominio artístico de Jimeno a las tierras aragonesas limítrofes con Guadalajara, y en concreto a la antigua Comunidad de

\footnotetext{
13 Acerca de estos dos retablos y la participación en ellos de Jimeno, vid. Marco Martínez, Op. Cit.

14 Urrea, Op. Cit. No todos los autores son de la misma opinión acerca de la procedencia de estas dos obras. Cfr. Ribera Blanco, Javier: "San Jerónimo", Las Edades del Hombre. La música en la iglesia de Castilla y León (catálogo de exposición). León, Diócesis de Castilla y León, 1991, p. 277.

15 Serrera, Op. Cit.

16 Gutiérrez Pastor, Op. Cit.
} 
Daroca. El hecho de que Jimeno buscase nuevos mercados más allá del ámbito castellano no es extraño, pues si bien no debieron faltarle encargos de particulares (cuadritos de caballete, labores de dorado e incluso tareas de brocha gorda), su estancia en Sigüenza a partir de 1644 coincide con un momento no especialmente activo en la construcción de retablos, lo que obligó a algunos artífices a buscar clientes en otros lugares; es el caso del ensamblador seguntino Pedro Castillejo, colaborador de Jimeno y que trabajó en la localidad turolense de Monterde de Albarracín ${ }^{17}$.

Valga también nuestra aportación para subrayar la importancia -que se revela cada vez mayorde la presencia e influencia de la pintura de raigambre madrileña en el barroco aragonés del s. XVII, esta vez a través de una vía intermedia como fueron las tierras de Guadalajara, donde dicha presencia fue también notable gracias a la actividad de artistas locales como Jimeno o bien mediante encargos puntuales ejecutados por artistas de esa escuela, como ocurre en el caso ya citado de Vicente Carducho o, ya mediada la centuria, con los trabajos para las iglesias de Atienza de Matías de Torres (1635-1711) y Alonso del Arco (1635-1704) ${ }^{18}$. Detrás de esta movilidad de artistas y obras -que enriquece y complica notablemente el hecho artístico y su estudio-, laten como es lógico motivaciones económicas, en un interesante fenómeno de "desplazamientos" en cadena que se producen en función de la competencia y la capacidad profesional de los artífices. No obstante, otros factores favorecieron los intercambios, y uno de ellos fue sin duda el de las divisiones eclesiásticas, no coincidentes con las actuales ni concordantes con los límites administrativos y judiciales de la época; a modo de ejemplo, la diócesis castellana de Sigüenza tuvo durante algún tiempo bajo su gobierno gran parte de la antigua Comunidad de Calatayud, que luego pasó a depender de la mitra de Tarazona.

\section{El retablo de la Asunción de Villanueva de Jiloca 19}

El retablo (565 x $350 \mathrm{cms}$.) (fig. 1) se sitúa en el extremo sur del transepto de la iglesia, encajado en el hueco de una capilla poco profunda que se cubre con bóveda de cañón. La mazonería de madera aparece en su color, sin dorar ni policromar, fenómeno que se repite en otros altares y que puede deberse a que los caudales de la parroquia tuvieran que destinarse a tareas más acuciantes como era la construcción de un nuevo templo, empresa que según algunos autores se llevó a cabo durante la primera mitad del s. XVIII 20.

El mueble litúrgico consta de sotabanco, cuerpo de calle y piso únicos, y ático. En el cuerpo, el lienzo principal está flanqueado por dos grupos de columnas trigeminadas de capitel corintio y fuste entorchado cuyo tercio inferior se decora con grutescos. En los netos de los plintos de las columnas centrales encontramos sendas figuras en medio relieve de Santa Águeda (izda.) y Santa Lucía (dcha.). Un sencillo entablamento da paso al ático, compuesto por una pintura que representa a Santo Tomás de Aquino flanqueada por dos columnas de fuste estriado en su parte superior y

\footnotetext{
${ }^{17}$ Marco Martínez, Op. Cit. El autor descarta la posibilidad de que los cuadros recogidos en un inventario de bienes post mortem de Jimeno y que habían sido encargados por Pedro Castillejo estuvieran destinados a los retablos mayores de Arbancón y de Monterde (quemado en la guerra civil), pues los lienzos de aquél están fechados en 1656 y la mazonería de éste estaba terminada en 1659.

18 Montaner, Op. Cit.

${ }^{19}$ La única referencia a este mueble litúrgico la hemos encontrado en: Mañas Pérez, Laura: "Reformas barrocas", Comarca del Campo de Daroca (coord. Fabián Mañas Ballestín), col. "Territorio" 8. Zaragoza, DGA, 2003, p. 217. En la enumeración de los retablos de la iglesia de Villanueva de Jiloca se cita el de la Asunción y se menciona el nombre del pintor, "Matías Gimeno", pero por una mala lectura o por error tipográfico se da una fecha equivocada (1581).

${ }^{20}$ Mañas Pérez, Op. Cit. Tal vez las obras del nuevo edificio se iniciasen con anterioridad, pues como se verá en el documento que aportamos, ya en 1654 se realizan obras en el coro bajo y se sube el nivel del suelo de la iglesia.
} 


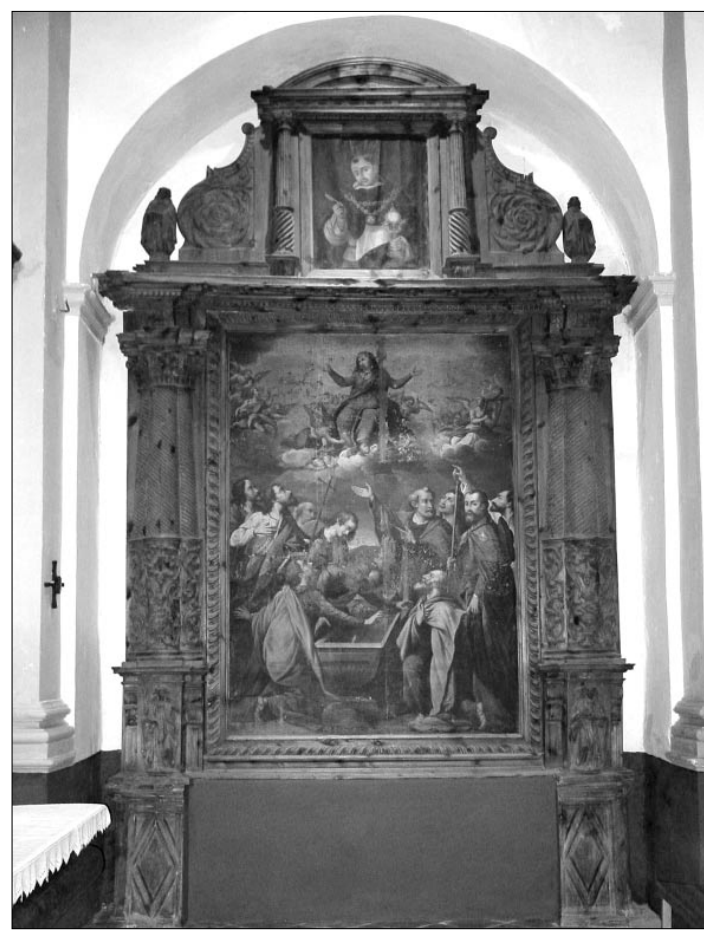

Fig. 1. Matías Jimeno, Retablo de la Asunción. Villanueva de Jiloca (Zaragoza).

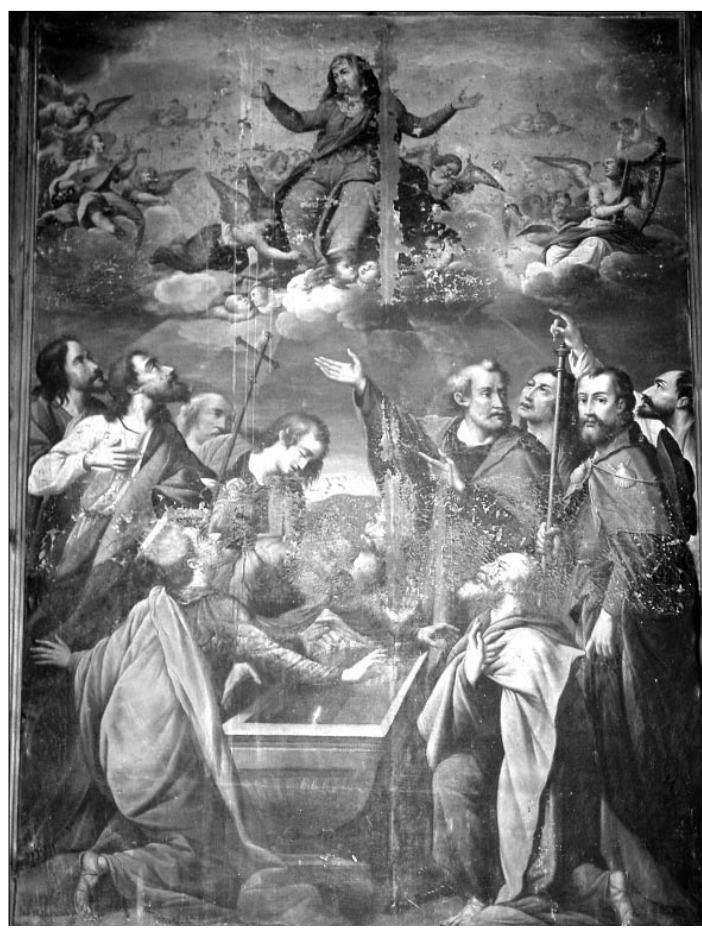

Fig. 2. Matías Jimeno, lienzo de La Asunción de la Virgen. Villanueva de Jiloca (Zaragoza).
Fig. 3. Matías

Jimeno, lienzo de

La Asunción de la

Virgen (detalle).

Villanueva de Jiloca

(Zaragoza).

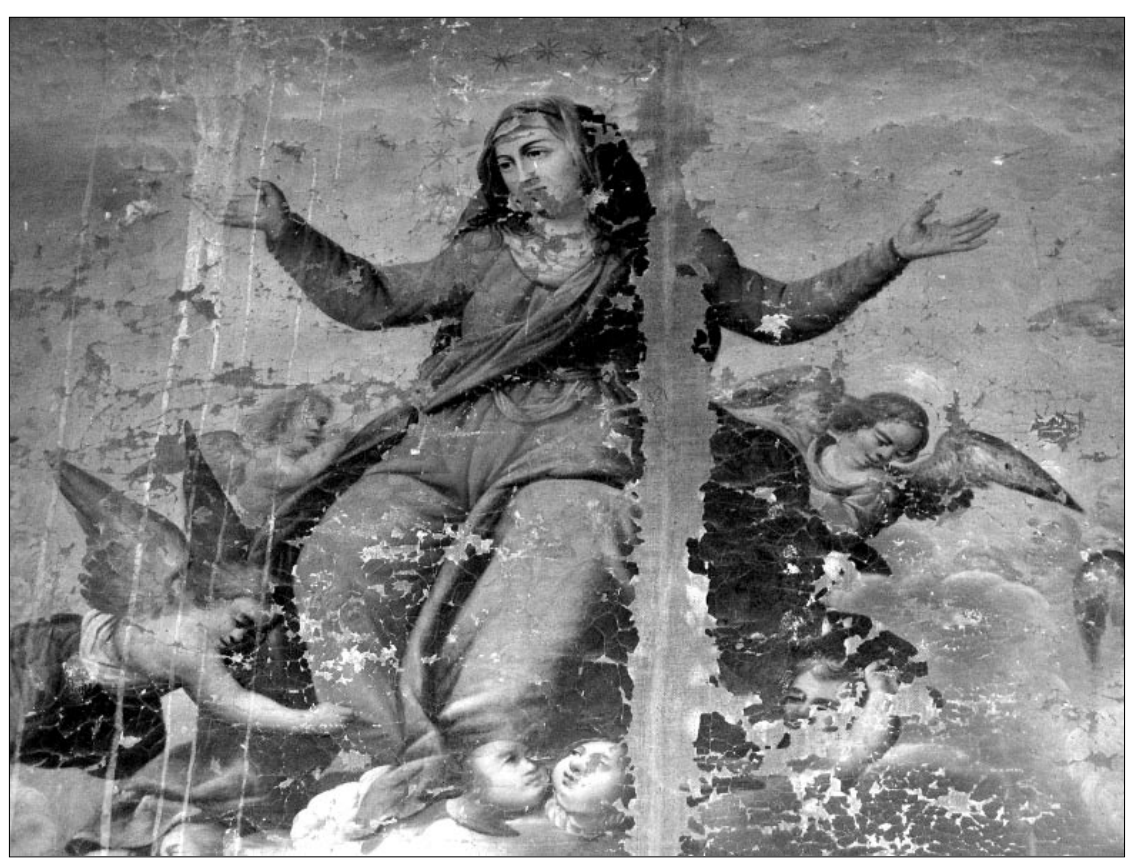

AEA, LXXIX, 313, ENERO-MARZO, 77-99, 2006, ISSN: 0004-0428 
entorchado en el tercio inferior. Dos adornos avolutados, un remate en forma de frontón curvo y, en los extremos, dos pequeñas imágenes de santas mártires sin identificar, completan la parte superior del retablo. El santo dominico se presenta de medio cuerpo y con su iconografía tradicional: hábito blanco y negro de su orden, amplia tonsura, cadena de oro de la que cuelga el medallón en forma de sol sobre su pecho y una pluma de ave y un ostensorio en las manos.

El lienzo principal ( $260 \times 185 \mathrm{cms}$.) (fig. 2), que presenta pérdidas localizadas de capa pictórica, nos presenta la escena de la Asunción de la Virgen con dos partes bien definidas. En la celestial, la Virgen sobre un trono de nubes y con los brazos extendidos está acompañada por un grupo de angelotes y querubines situado a sus pies (fig. 3) y por otros dos grupos de ángeles músicos y cantores en los laterales; todo este conjunto, tratado con tonos y modelado suaves, destaca sobre un fondo de resplandor difuminado en tonos amarillos cálidos. La parte terrenal (figs. 4 y 5), que adquiere mayor protagonismo al ocupar las dos terceras partes del cuadro, nos ofrece una composición igualmente equilibrada y algo apelmazada con seis apóstoles situados a cada lado del sepulcro vacío y una mínima concesión al paisaje en la parte central; las figuras, aunque algo estereotipadas, adoptan posturas y gestos diferenciados que aportan cierta sensación de movimiento y "vida", si bien la contención y gravedad expresiva de los personajes y la uniformidad de sus rostros restan credibilidad y emoción al cuadro. El tratamiento pictórico de esta parte es algo más duro, con una pincelada apretada y un modelado acusado. Se observa recreación en los pliegues de las ropas y gusto por el detalle, así como el uso de un cromatismo de raigambre veneciana. En general se deduce de esta obra la intervención de un pintor buen conocedor del oficio, aunque limitado en su alcance artístico, que poseía los recursos suficientes para resolver composiciones de cierta complejidad.

La firma (fig. 6) se sitúa en la base del sepulcro: "Mathia Jimeno Apinxit / Anno 1656" y presenta como peculiaridad el uso de la expresión "apinxit" en lugar de la habitual "faciebat".

En cuanto a los modelos utilizados, las mayores concomitancias (pues no puede hablarse de copia fiel) las hemos encontrado en un cobre atribuido al taller de los Zuccaro ${ }^{21}$ del que no conocemos estampa, aunque la inversión compositiva parece avalar su existencia ${ }^{22}$. Sin embargo, para los ángeles músicos Jimeno hizo uso parcial de la célebre composición de Federico Zuccaro Anunciación con profetas, grabada entre otros por Rafael Sadeler y Cornelis Cort (figs. 7 y 8).

Es preciso señalar que, en el mismo año 1656, Jimeno firmó dos de los seis lienzos que había contratado en el mes de enero con el ensamblador Pedro Castillejo para el ya mencionado retablo de Arbancón. La calle central del tercer piso de esta gran máquina está ocupada por un lienzo de la Asunción que no figura en la escritura notarial; este hecho, unido al recrecimiento en altura del retablo -que probablemente se llevó a cabo hacia 1680, coincidiendo con el proceso de dorado ${ }^{23}$, nos hace dudar de la autoría de nuestro artista para esta pintura ${ }^{24}$. Sea como fuere, y además de

21 Asunción de la Virgen, óleo sobre cobre, 56 x 42 cms. Madrid, Museo del Prado, inv. 286. Reproducido en: Pérez Sánchez, Alfonso E. (coord.): Museo del Prado. Inventario general de pinturas. I.-La colección real. Madrid, Museo del Prado-Espasa Calpe, 1990, p. 504, núm. 1896.

22 La existencia de una estampa puede darse por segura, pues hemos localizado otra pintura que copia, al menos en la parte terrenal, la citada composición (esta vez sin inversión). En concreto, se trata de un lienzo firmado en 1618 por un desconocido Lorenzo de Aguirre que se conserva en la sala capitular de la catedral de Mondoñedo (Lugo) y que fue dada a conocer por el profesor Juan M. Monterroso. Monterroso Montero, Juan M.: "Algunos ejemplos aislados de la presencia de pintura barroca española y flamenca en Galicia", Cuadernos de Estudios Gallegos. Santiago de Compostela, t. XLIII, fascículo 108, 1996, pp. 244-246. El autor ya puso en relación esta obra con la Asunción pintada en 1587 por Federico Zuccaro para el retablo mayor de El Escorial, si bien las diferencias entre la composición escurialense y la del cobre del Museo del Prado son abundantes.

23 Marco Martínez, Op. Cit.

24 No hemos visto esta obra in situ, y las imágenes de que disponemos no ofrecen la suficiente definición, lo que nos impide establecer una comparación entre las dos versiones del tema. 
Fig. 4. Matías

Jimeno, lienzo de

La Asunción de la

Virgen (detalle).

Villanueva de Jiloca

(Zaragoza).

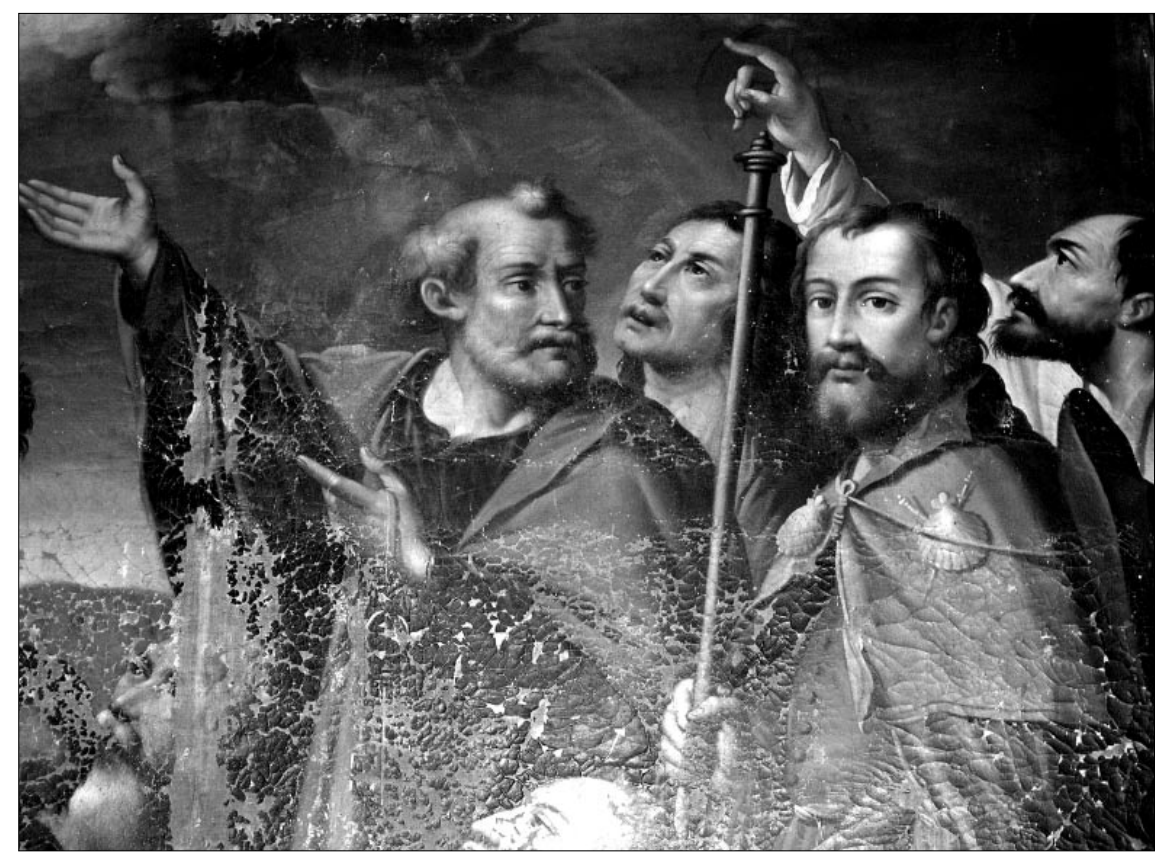

Fig. 5. Matías Jimeno, lienzo de La Asunción de la Virgen (detalle). Villanueva de Jiloca

(Zaragoza).

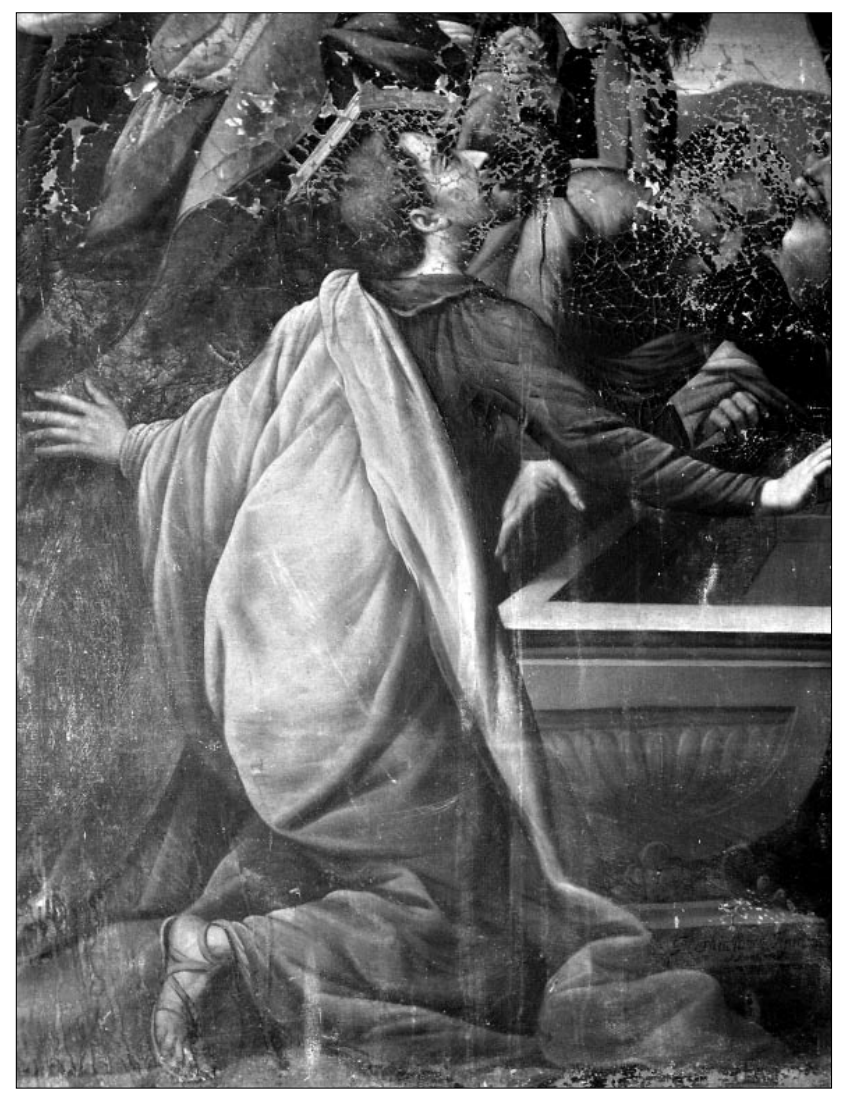

AEA, LXXIX, 313, ENERO-MARZO, 77-99, 2006, ISSN: 0004-0428 
los referentes grabados, Jimeno hubo de conocer, a lo largo de su trayectoria artística, versiones pictóricas ajenas de este mismo asunto. Una de ellas la pudo ver precisamente durante su temprana estadía en Pastrana; nos referimos a una pintura sobre ágata situada en el sagrario del retablo mayor de la colegiata pastranense, firmada en 1624 por el pintor francés Jacques Stella, quien planteó la composición limitando la escena a la parte celestial, con la Virgen rodeada de una gloria de ángeles. La obra había sido regalada por el papa Urbano VIII al III duque de Pastrana, quien a su vez la dio al arzobispo, de cuyas manos pasó finalmente al cabildo de Pastrana, quien aceptó la donación en $1635^{25}$. A propósito de la estancia de Jimeno en esta localidad y del uso frecuente que el pintor hace de estampas norteuropeas, no nos resistimos a plantear, como hipótesis de trabajo, la posible incidencia que en este hecho pudo tener la presencia de una importante colonia de ciudadanos flamencos - pero también italianos y portugueses-, muchos de ellos artistas, que recibieron la protección de los duques ya desde la segunda mitad del s. XVI y durante la primera mitad del XVII 26. Este contingente sirvió a su vez de "cabeza de puente" para otros individuos de esa nacionalidad dedicados al comercio, y sin duda fue una clientela ávida de modelos grabados, que utilizaban habitualmente en su trabajo. Entre los pintores flamencos activos en Pastrana en ese periodo están Isabel de Amberes (documentada en 1587) y Francisco de Cleves (documentado en 1606); este último fue criado del tercer duque (Ruy Gómez de Silva de Mendoza y de la Cerda) y en su testamento declaró poseer 295 estampas 27 . Otro magnífico ejemplo, bien estudiado ${ }^{28}$, de esta presencia flamenca es el tapicero bruselés François Tous, activo desde 1622 hasta su muerte en 1633, si bien la manufactura de tapices iniciada por él y financiada por el tercer duque continuó algunos años más -tal vez hasta la década de 1640-; sabemos que Tous hizo uso de modelos italianos para algunos de sus tapices, pues parece que agradaban especialmente a su protector. No obstante, con anterioridad a 1622 funcionaba ya en esta villa castellana una industria sedera en cuyo trabajo y comercialización participaban portugueses y flamencos, circunstancia que, unida a la presencia de buenos tintoreros y a la calidad del agua, pudo condicionar la elección de Pastrana, aunque en la decisión resultara definitiva la intervención del duque ${ }^{29}$.

\section{El encargo y el encargante}

La iniciativa y el encargo para la realización del retablo de la Asunción correspondieron al entonces vicario de la parroquia de Villanueva de Jiloca, mosén Tomás Mateo Malo, quien el 8 de diciembre de 1654 solicitó y obtuvo licencia para fabricar una capilla a sus expensas, dedicada al Señor y a la Asunción de la Virgen; en la capitulación ${ }^{30}$ se establecen las condiciones -en general de un marcado carácter altruista-impuestas por el peticionario, entre ellas que el lugar se haría cargo del vaciado y desescombro previos del espacio destinado a la capilla; que el vicario se reservaba para él y los suyos el derecho de tres sepulturas en la cisterna hecha al efecto; y que la capilla contaría con una dotación de al menos quinientos escudos de censal. En el mismo documento se

25 Torres-Peralta García, Ma. Jesús de: "Una obra inédita de Jacques Stella en Pastrana (Guadalajara)", Archivo Español de Arte. Madrid, 224, 1983, pp. 377-379.

${ }^{26}$ García López, Aurelio: "La comunidad flamenca en la España de los Austrias: la marginación de los pintores flamencos de Pastrana (Guadalajara)", Wad-Al Hayara. Guadalajara, 26, 1999, pp. 155- 181.

27 García López, Op. Cit., pp. 172 y 176.

28 Asselberghs, Jean-Paul; Delmarcel, Guy; y García Calvo, Margarita: "Un tapissier bruxellois actif en Espagne: François Tous", Bulletin des Musées royaux d'Art et d'Histoire de Bruxelles. Bruselas, t. 56, Fas. 2 (1985), 1987, pp. 89-121.

${ }^{29}$ Siguiendo el modelo adoptado en Francia en 1607, Tous solicitó el permiso real para la instalación en Pastrana en 1621, con la condición de detentar el monopolio a nivel español durante treinta años.

${ }^{30} \mathrm{Vid}$. apéndice documental, 1. 
Fig. 6. Matías Jimeno, lienzo de $L a$ Asunción de la Virgen (detalle con la firma). Villanueva de Jiloca (Zaragoza).

Fig. 7. Cornelis Cort según Federico Zuccaro, grabado de $L a$ Anunciación con profetas (detalle)

Fig. 8. Cornelis Cort según Federico Zuccaro, grabado de $L a$ Anunciación con profetas (detalle).
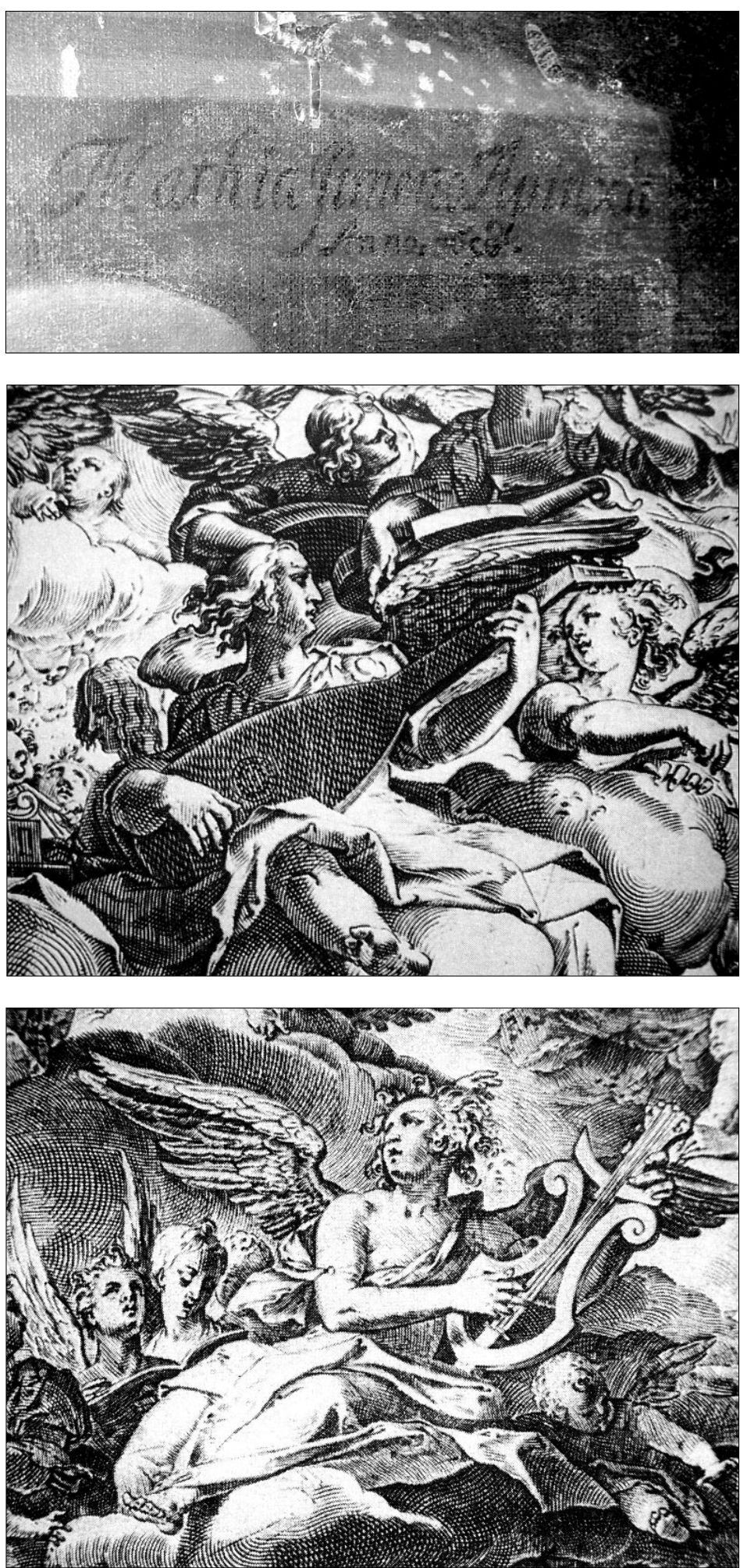

AEA, LXXIX, 313, ENERO-MARZO, 77-99, 2006, ISSN: 0004-0428 
dice que el 15 de octubre de 1655, fecha en que Tomás Mateo firmó la citada capitulación en el libro del concejo, “... ya estaba la capilla toda fabricada y solo restaba el retablo", lo que permite situar la realización del mismo entre esa fecha y el año 1656 en que Jimeno firma el cuadro central. Ignoramos por ahora cómo y cuándo pudieron entrar en contacto cliente y artista, y no hemos localizado contrato alguno ni de la mazonería del retablo ni de la parte pictórica del mismo.

De Tomás Mateo Malo sabemos que era hijo de Juan Mateo y Lucía Toro. Nació en Villanueva de Jiloca, donde fue bautizado por su tío y entonces vicario perpetuo de la parroquia, mosén Juan del Toro, el 27 de diciembre de 1609, y el 27 de octubre de 1613 fue confirmado por el arzobispo de Zaragoza Pedro Manrique en el lugar de San Martín del Río (Teruel) ${ }^{31}$, donde residía parte de su familia y adonde él mismo se retiró en sus últimos años de vida. Tomó posesión de la parroquia de Villanueva, sucediendo a su tío, el 18 de octubre de 1633; lo hizo de forma extraordinaria antes de cumplir los 24 años (edad mínima establecida por el Concilio de Trento para los beneficios curados) merced a una dispensa de seis meses dada por Roma, y dijo misa por vez primera el último día de marzo de 1634. Desempeñó el cargo hasta 1668, en que le sustituyó su sobrino, el licenciado Juan Sancho ${ }^{32}$, y falleció el 22 de agosto de 1674, habiendo testado tres años antes ${ }^{33}$. Su actuación como benefactor de la parroquia no sólo se limitó a la dotación artística y económica de la capilla, pues en 1662 fundó una capellanía ${ }^{34}$, cuyo acto de institución fue protocolizado por Blas Solanas, notario público de Daroca, el 30 de octubre de ese año; en el documento de institución se establece la celebración de 156 misas rezadas -más diez que se añadieron en 1671- en el altar “... de mi Capilla de la Asuncion de la Virgen SS ${ }^{m a}$.”, y la asignación para estos fines de trescientos sueldos jaqueses de pensión anual con seis mil sueldos de propiedad cargados sobre censales del lugar de Villanueva según instrumento público testificado a 28 de octubre de 1646 por Juan José Sánchez, notario real domiciliado en San Martín del Río ${ }^{35}$. En sus últimas voluntades, protocolizadas el 16 de septiembre de $1671^{36}$, dispuso que su cuerpo fuese sepultado “... delante del Altar de la Asumption de la Virgen Santissima en la capilla de su assumption gloriosa que yo edifique a mis espensas"; entre las mandas testamentarias, una se refiere a la donación a la parroquia de "... un niño Jesus de bulto sobredorado y los ornamentos de deçir misa que al tiempo de mi muerte se hallaren en mi poder", y otra a su sobrino Juan Sancho, a quien lega -además de varios bienes sitios, “... dos quadros de los que yo tengo los que quisiese escoger a su deboçion y dos sillas de cuero".

\footnotetext{
31 Archivo Diocesano de Zaragoza (A.D.Z.), Carpeta de procesos beneficiales de Villanueva de Jiloca, Proceso de ejecución de letra apostólica a favor de Tomás Mateo sobre colación de la vicaría de Villanueva de Jiloca, vacante por resignación de Juan del Toro en 1633, papel inserto donde figura la copia de la partida de bautismo y la confirmación de Tomás Mateo Malo, firmada por el regente Domingo Mara en 1633.

32 A.D.Z., Libros parroquiales de Villanueva de Jiloca, t. III (1650-1690), Cinco libros de la Iglesia del lugar de Villanueba hecho el año 1650, papel suelto a modo de índice.

33 A.D.Z., Libros parroquiales de Villanueva de Jiloca, t. III (1650-1690), Cinco libros de la Iglesia del lugar de Villanueba hecho el año 1650, "Libro de los Muertos", f. 42 r.

34 A.D.Z., Libros de culto y fábrica de Villanueva de Jiloca, t. IV, Libro de las Capellanías fundadas en la iglesia parroquial de Villanueva de Xiloca, echo este año de mil setencientos y uno 1701, ff. 21 r.-24 r. (una agregación de diez misas, en ff. 25 v.-26 v.)

35 Archivo Histórico de Protocolos de Daroca (A.H.P.D.), not. Diego Antonio Sancho, caja núm. 2328 (años 16651674), 1671 (17 de diciembre), ff. 224 v.-227 v.

36 Loc. cit., sin foliar.
} 


\section{Apéndice documental}

1655 , octubre, 15

Villanueva de Jiloca

Capitulación y condiciones establecidas por Tomás Mateo Malo y aceptadas por el lugar de Villanueva de Jiloca para fabricar una capilla dedicada a la Asunción de la Virgen en la iglesia parroquial de San Gil Abad.

Archivo Diocesano de Zaragoza (A.D.Z.), Libros parroquiales de Villanueva de Jiloca, t. III (1650-1690), Cinco libros de la Iglesia del lugar de Villanueba hecho el año 1650, "Libro de Bautiçados", ff. 90 r.-91 r.

"/f. 90 r./ En 8 de deçiembre del año de 1654 Moss. Thomas Matheo Malo vicario de esta parroquial considerada la cortedad desta yglesia y mobido del aumento del culto divino y de que el templo del Señor este con mas decençia y los fieles con mas comodidad para asitir [sic] a los ofiçios divinos demandó licençia al lugar para fabricar una capilla a sus espensas a gloria y onrra del Señor y de la asumption de la virgen Santissima su prinçipal adbogada y señora. El dicho lugar todo mui conforme y gustoso le conçcedio liçençia y facultad para que la fabricase segun arte y a su disposicion y el dicho con açimiento de graçias lo acceptó y tubo a grande dicha, y dio una capitulaçion de su mano con las condiçiones que aqui se diran y lo acepto todo el lugar

$1^{\circ}$ [en el margen] que dicho vicario ha de açer la capilla a sus espensas y gastos solo que el lugar a de baçiar la pieza que ay en dicha capilla por estar mas alta que la yglesia y lo que caera de las paredes y obra y tambien da para el ofiçial el espojo de los ladrillos y piedra que se hallase escepto la madera de un suelo de granero que hay ençima.

$2^{\circ}$ [en el margen] que es voluntad de dicho vicario que en dicha capilla puedan entrar i estar y asentarse todo genero de personas assi hombres como mugeres a oyr misa y los ofiçios divinos y particularmente los pobres y sirbientes en el lugar lo qual les ruega por dios lo agan sin liçencia alguna y sin que persona alguna se los pueda ynpedir ni estorbar

$3^{\circ}$ [en el margen] que del mesmo modo se puedan enterrar en ella qualesqquiere genero de fieles pagando la jocalia al lugar conforme la demas yglesia y poner asi en la sepultura en la conformidad que en la de la demas /f. $90 \mathrm{v}$,/ de la yglesia se permite y açe y si no se yçiese no porque su animo no es ynnobar cosa alguna de conforme lo demas esceptando para si tan solamente tres sepulturas donde quisiere, $o$, eligiese una para si y las otras para sus hermanos guesos de sus padres y su thio Moss. Juan del Toro vicario que fue de dicho lugar y predecesor suyo si le pareçiere trasladarlos y estas tres sepulturas se las conçedio el lugar libres de jocalia en todo tiempo para el y los suyos suçesores deudos [siguen unas palabras ilegibles tachadas en el original]

$4^{\circ}$ [en el margen] que assi el vicario que fuere de dicho lugar y los clerigos de la yglesia y jurados juntos todos y cada uno de por si sin otra liçencia que querer puedan en dicha capilla poner confesonario parar las andas para açer las proçesiones haçer en ella el monumento y todo lo demas que fuere necesario a dicha yglesia para el culto divino pues no sean cosas [que tachado] en demasiado desadorno de dicha capilla por quanto el animo del dicho no a sido açer capilla para sus deudos porque por ello no se ensoberbe confirmo para maior aumento del culto divino que el dicho reserba para el patron que yra suzediendo asiento preeminente a los demas exceptando que si los señores jurados asistiesen a alguna fiesta en ese caso es su voluntad le prefieran al patron a qualquiere que sea y que en ningun tiempo por estorbar pesares y contiendas no se pueda poner ninguna silla ni otro genero de asiento que los que comunmente se acostumbran en dicha yglesia que el dicho vicario la dota de presente con quinientos escudos que tiene çensales y si dios le diese [mas tachado] promete dotarla mas. Assimesmo por estorbar todo genero de pelitos [sic, por pleitos] y contiendas en los tiempos venideros le pareçio no ubiese otra escritura ni obligaçion sino esta memoria para que conste de la /f. $91 \mathrm{r}$./ verdad y obra en la misma conformidad junto con la capitulaçion que de mi mano en el libro del conçejo por ser asi 
todo verdad lo firme de mi mano y nombre en 15 de octubre del año 1655 que ya estaba la capilla toda fabricada y solo restaba el retablo.

Mosse. Thomas matheo malo $\mathrm{v}^{\mathrm{O}}$. Mi edad quarenta y çinco años

Por el mismo consiguiente luego que se conçerto la capilla determino el lugar açer el coro bajo cortando la torre de todo lo qual se le siguio gran aumento y deçencia a la yglesia costo el coro cien escudos y se hiço la paga de la limosna que para ello dieron los beçinos se subio la yglesia que estaba mas onda y otras muchas cosas que se hiçieron todo fue en el año de 1654".

JuAN CARLOS LOZANo LÓPEZ

Universidad de Zaragoza 